\title{
Correction to: Observing Justice at Guantánamo Bay: Human Rights NGOs and Trial Monitoring at the US Military Commissions
}

\section{Kjersti Lohne ${ }^{1}$ (D)}

Published online: 19 June 2021

(c) Springer Nature B.V. 2021

\section{Correction to: Human Rights Review https://doi.org/10.1007/s12142-021-00619-z}

The original version of this article unfortunately contained mistakes introduced during the production process. The corrections are given in the following list:

1. In "Guantánamo Bay as Extra-judicial Space" section, third paragraph, line 24, 'should be "habeas"' should be deleted. The sentence should be rewritten as:

This ambiguous legal space enabled the Bush administration to claim that its detainees at Gitmo had no constitutional rights before US courts, including the right to challenge their detention through a hebeas corpus petition (a claim later overturned by the US Supreme Court in the 2004 ruling in Rasul v Bush).

Also, in line 32, the sentence "These next two paras should also be indented." should be deleted.

2. In "Trial Monitoring at Guantánamo Bay” section, second paragraph, line 1, 'delete "on Human Right Reporting" on Human Rights Reporting' should be deleted

The original article has been corrected.

Publisher's Note Springer Nature remains neutral with regard to jurisdictional claims in published maps and institutional affiliations.

\footnotetext{
Kjersti Lohne

kjersti.lohne@jus.uio.no

$1 \quad$ University of Oslo, Postbox 6707, St. Olavs plass, Oslo, Norway
}

The online version of the original article can be found at https://doi.org/10.1007/s12142-021-00619-z 